\title{
Effects of physical activity on anthropometric variables and functional capacity of patients with type 2 diabetes
}

\author{
Robson Bonoto Teixeira1', Luciana Moreira Lima², Yuri Lucas Xavier', Carlos Gabriel de Lade³, Gabriela Fernandes Lopes', \\ Hamilton Henrique Teixeira Reis' ${ }^{1}$ João Carlos Bouzas Marins ${ }^{4}$
}

\begin{abstract}
Introduction: Type 2 Diabetes Mellitus affects current society, and is associated with overweight and obesity. Physical exercise has been showing favorable results in the anthropometric parameters and in the gain of joint flexibility and body mobility in these individuals. Objective: The objective of this study was to analyze the interference of an exercise program in anthropometric measures, flexibility and body mobility in type 2 diabetics. Method: This is a longitudinal study, performed with 14 type 2 diabetic patients, with a mean age of $55 \pm 9$ years, both genders, separated in aerobic group $(n=8)$ and resistance group $(n=6)$. The body mass index, waist circumference, abdominal circumference, hip circumference, waist-hip ratio, fat percentage, limp-femoral flexibility and body mobility were assessed before and after a 10-week period of aerobic or resistance exercises with a weekly frequency of 3 days. Results: For the analysis of the results, it was applied the paired $t$ test (pre x post exercise) and independent $t$ test (aerobic group $x$ resistance group) with significance level of $5 \%$. No significant differences were found in the anthropometric variables in both groups after the 10 -week period of supervised training. In relation to the body mobility test, we observed a significant difference in the total sample ( $p=0.02)$, in the aerobic group $(p=0.02)$ and in the resistance group $(p=0.04)$. The coxofemoral flexibility test showed significant improvement $(p=0.02)$ in the total sample and clinical improvement in aerobic $(p=0.12)$ and resistance $(p=0.09)$ groups. Conclusion: Both aerobic and resistance training provided positive effects in the coxofemoral flexibility and body mobility tests. In contrast, there was no significant improvement in anthropometric variables after 10 weeks of physical exercise.
\end{abstract}

Keywords: Diabetes Mellitus, Exercise, Flexibility, Body Composition.

\section{INTRODUCTION}

Diabetes mellitus is a chronic metabolic disease that provides alarming statistics on morbidity and mortality with a worldwide perspective that 360 million people may have the disease in 2030. ${ }^{(1)}$ In Brazil, the prevalence is around $21.1 \%$ for the population of 30 to 69 years. Specifically in the State of Minas Gerais (MG) the expectation is that $11.9 \%$ of the elderly have Diabetes mellitus. ${ }^{(2)}$

Physical exercise is pointed as a fundamental practice for the prevention and treatment of Diabetes mellitus. ${ }^{(3)}$ When practiced in a regular way and associated to stretching may provide more flexible joints and maintenance of the corporal and coordinating balance, resulting in greater mobility and independence. ${ }^{(4)}$ Thus, the intervention of a regular physical exercise program is considered fundamental in diabetics, with specific guidelines proposed by the American Diabetes Association. ${ }^{(5)}$

The prevalence of overweight and obesity in patients with Type 2 Diabetes mellitus (2DM) is three times higher than in general population. ${ }^{(6)}$ Data from Health Unic System (HUS) demonstrated that 2DM is among the top 10 causes of death in the country. To verify the levels of obesity in diabetics, the anthropometry has been recommended to assess the body composition for being a method of easy clinical applicability and with low cost. ${ }^{(7)}$ Among the anthropometric measurements indicated for clinical verification of excessive body mass, is emphasized the perimeter of waist, the body mass index (BMI) and the waist-hip ratio (WHR), besides the abdominal perimeter and the percentage of body fat through the skin folds, which is widely used for complementary supply as to the distribution of body fat. ${ }^{(8-10)}$

Moreover, stretching performed periodically can induce the acquisition of adequate flexibility, resulting in the prevention of injuries and delayed muscle pain, leading to an improvement in physical performance and quality of life. ${ }^{(11)}$

It is important to verify the magnitude of the impact of physical activity insertion and to compare whether 
the type of exercise prescribed in a systematized form (aerobic or resistance training) has a different impact on the anthropometric aspects and the functional capacity of patients with 2DM to better guide the prescription form of exercise for this population. The objective of the present study was to analyze the effects of regular physical exercise on the anthropometric and functional capacity parameters in patients with 2DM belonging to a supervised physical exercise program, as well as to evaluate and compare the results between aerobic and resistance exercise programs.

\section{METHOD}

This study is a longitudinal type investigation. All the patients were informed about the methodology and objectives of the study and signed the Free and Informed Consent Form, approved by the Human Research Ethics Committee of the Federal University of Viçosa, under the CAAE $\mathrm{n}^{\circ}$ 28144814.0.0000.5153.

Our study contemplated all the ethical principles set in the Helsinki Declaration, which protect the volunteers involved in the practice of research, ${ }^{(12)}$ so this study is in accordance with the specific legislation of our country.

\section{Sample}

The study was started with a total of 20 patients with $2 \mathrm{DM}$, but six volunteers abandoned their research during the exercise routine, for several reasons: financial difficulty to travel to the Hiperdia Center, for surgeries (umbilical hernia, cataract), event of cardiac ischemia and also for personal reasons. Therefore, the study was carried out with a sample of 14 patients, nine female and five male. All the volunteers were participants in the supervised physical exercise program of the Hiperdia Center of Viçosa/MG, intended for the registration and follow-up of hypertensive and/or diabetic patients attended by HUS. The inclusion criteria were considered patients with 2DM, of both genders, over 18 years, not practitioners of routine and/or systematized exercise. As for the exclusion criteria were: type 1 diabetics; Patients with peripheral arterial disease; Illicit drug users; Congestive heart failure and decompensated lung disease; Symptomatic cardiac arrhythmia; Orthopedic or rheumatic diseases that would make it impossible to perform the proposed exercises; Signs of acute cardiac ischemia during the ergometric test; And symptomatic cardiac arrhythmia provoked by the ergometric test.

\section{Instrument}

All patients were assessed by submaximal trait ergometric test (ET) in ramp protocol, prior to participation in the study, performed by a cardiologist in the Hiperdia Center following the guidelines of the Brazilian Society of Cardiology with the objective of possible diagnosis of cardiovascular diseases. (13) The utilization of submaximal ET was due to the high degree of affection presented by the patients attended at the Hiperdia Center of Viçosa/MG. All of them demonstrated clinical pictures very worrisome, related with the progress of complications of hypertension and 2DM, preventing the use of the submaximal ET. In addition, the study participants presented low physical fitness, low motor coordination and low ergometer adaptation. In view of the sample complications, it was impracticable to use the maximum repetition test to obtain the training loads.

The body mass was measured using the Mercy ${ }^{\circledR}$ (LC 200 model, Brazil, 2010) balance, with scale ranging from 1 to 200 kilograms and 50 grams of precision. The atature was assessed through the Welmy ${ }^{\circledR}$ (R110 model, Brazil, 2009) stadiometer, with scale ranging from 0,8 to 2,00 meters and 1 millimeter of precision. The BMI was calculated through the BMI formula (BMI=peso corporal $(\mathrm{kg}) /$ altura $(\mathrm{m})^{2}$ ). The cut limits adopted were those recommended by the World Health Organization. ${ }^{(14)}$ The waist, abdomen and hip perimetry were measured using Proximus ${ }^{\circledR}$ (Rio de Janeiro, Brazil, 2013) retractable and flexible tape measure, with scale ranging from 0 to 200 centimeters and 1 millimeter of precision. ${ }^{(14)}$ Abdominal perimetry was measured at the midpoint between the tenth rib and the upper border of the iliac crest, as recommended by Freedman et al. ${ }^{(15)}$ Waist perimetry was measured in the thinner region of the abdomen, the Hip perimetry in the perimeter of greater extension between the hips and the buttocks and the WHR was calculated by the division of the perimetry of waist and hip. ${ }^{(16)}$ As for measures of skinfolds was used the Cescorf ${ }^{\circledR}$ Mitutoyo (Brazil) compass, with reading range of 88 millimeters and accuracy of 0,1 millimeter. The skinfolds were obtained through the equation proposed by Jackson \& Pollock ${ }^{(17)}$ to male and by Jackson et al. ${ }^{(18)}$ to female, in which was used the sum of three skinfolds, being them the pectoral, abdominal and mid femoral folds for male and tricipital, abdominal and mid femoral for female. For the conversion of body density to body fat percentage, the equation proposed by Siri was used, using the sum of the skinfolds. ${ }^{(19)}$ All data were collected by an experienced physical evaluator, using the Avaesporte ${ }^{\circledR}$ software.

After obtaining the anthropometric data, the subjects were submitted to a physical mobility test with the objective of evaluating the speed, agility and dynamic body balance. The test consisted of a chair supported against the wall, with a cone in front of it at a distance of 2,44 meters (measured from the tip of the chair to the front of the cone). The test started with the volunteer sitting in the chair with his hands on his thigh and his feet fully resting on the ground. At the sign of "departure" the volunteer got up from the chair, walked as fast as possible to the cone, rounded it and returned to the chair in the starting position. Other studies have already applied this protocol, such as the study of Alves et al. ${ }^{(20)}$ The other test was Wells' bench, with the purpose of evaluating the hip flexibility. 
The participants sat with their knees fully extended and feet resting on the underside of Wells' bench, placing one hand over the other, with the index fingers joined and overlapping. From this position, they projected the trunk ahead flexing it to the maximum, with the head meeting between the arms. The position was held for 2 seconds for reading. ${ }^{(21)}$ The tests were composed of three trials, in which the best was considered. All the anthropometric measurements were performed by the same researcher before and at the end of the intervention, as well as the Wells bank and the body agility test.

\section{Procedures}

After the evaluation stage, the volunteers started the routine of supervised exercise. The exercises were prescribed, respecting the limitations and potential of each patient identified in the initial evaluations, and followed the international guidelines for diabetics proposed by the American College of Sport Medicine and the American Diabetes Association. ${ }^{(5,22)}$

Participants in the study underwent physical exercise intervention, often three times a week, for 10 weeks. All training sessions were supervised by physical educators, doctors and nurses at the Hiperdia Center of Viçosa/MG. An adherence of $90 \%$ to the program was determined so that the results were valid, in which participants were randomly divided into two groups, corresponding to aerobic and resistance exercises. The group that corresponded to aerobic training (AT) was composed of eight patients and the resistance training group (RT) of six patients. Aiming at the safety of volunteers throughout all exercise sessions, capillary blood glucose and blood pressure measurements were performed before, during and after the session.

Participants of the RT underwent warming up for 10 minutes in an intensity of $50 \%$ of maximal heart rate (MHR), estimated by the equation of Tanaka et al. ${ }^{(23)}$ From this moment on, the resistance exercises were started in circuit method, composed of the following 10 exercises: neutral rowing, squatting, dumbbell bench press, knee extension with leggings, dumbbell shoulder press, dumbbell curl, dumbbell knee flexion, standing plantar flexion, triceps cable pushdowns and abdominal flexion of trunk. Due to the low physical conditioning and motor coordination of the patients, the initial loads of each exercise were stipulated according to their perceived exertion, using the scale of 6 to 20 proposed by Borg, in which the scale values used were 11 to 13 , representing moderate effort. ${ }^{(24)}$ With the progress of the movement pattern and the physical conditioning, and from the report of the participants, the loads were adjusted. The volunteers performed two sets of 15 repetitions in the first two weeks, with the purpose of adapting the neural, articular and muscular systems. From the second week, the training consisted of three sets of 12 repetitions, in which a pause occurred between the second and third series to obtain measurements of capillary blood glucose and blood pressure. The mean time of each complete exercise session was 60 minutes from the third week.

To the AT group, also aiming for a suitable physiological and motor adaptation, the duration of the main part of the sessions was of 30 minutes of continuous exercise in the first two weeks, evolving to 40 minutes in the following weeks, until the end of the training period. In order to motivate the volunteers and minimize the monotony during the training sessions, the participants were stimulated to alternate cycle ergometers during the sessions, in which the options of cycle ergometers were: treadmill, exercise bicycle and elliptical. Initially, there was a proposal to control training intensity through the percentage of MHR, estimated by the equation of Tanaka et al. ${ }^{(23)}$, as well as occurred in the RT group. However, in this group 5 patients used adrenergic beta blockers to control blood pressure, making it impossible to use heart rate for intensity control. As in the RT group, the scale of subjective perception of effort proposed by Borg was used, respecting the values of 11 to 13 that represent a moderate effort. ${ }^{(24)}$ For patients who did not have arterial hypertension or who did not use beta-blockers, initial planning was maintained. Regarding the return to calm, the same procedures of the RT group were used, totaling an average time of 60 minutes per training session from the third week. After 10 weeks of inclusion in the proposed exercise program, volunteers were reassessed using the same initial protocol by the same evaluator.

\section{Statistical Analysis}

Descriptive statistics (mean and standard deviation) were used to characterize the sample. The Shapiro-Wilk normality test was used. Considering that the data showed a normal behavior, the paired t-test was used to observe the significance between the pre- and post-training moments in both the resistance group and the aerobic exercise group. The Mann Whitney test was used when the data did not present normality between men and women in body mass and in abdominal perimetry. The level of significance adopted for the tests was $5 \%$. The data were analyzed using the SPSS Statistics 20 software.

\section{RESULTS}

The Table 1 shows the caracteristics of the sample: 14 patients with $2 \mathrm{DM}$, with mean age of $55 \pm 9$ years, with predominance of female (64\%). It was observed a high BMI in the studied population, in which all the female had a percentage of fat over $35 \%$, and $60 \%$ of the male showed values above $25 \%$ and that is considered the limit for characterization of obesity according to the World Health Organization (WHO). ${ }^{13}$ All the female presented abdominal perimetry above $80 \mathrm{~cm}$ and $80 \%$ of the male presented values above $94 \mathrm{~cm}$. Recommended as limit values for good cardiovascular health. ${ }^{13}$ In relation to WHR, $100 \%$ of female 
and male showed values above 0.85 and 0.90 , respectively, also instituted by WHO as limit values, thus showing a population with a high risk of developing cardiovascular diseases. ${ }^{13}$

After 10 weeks of training with supervised exercise, small improvements were observed in BMI, waist perimetry, abdominal perimetry, WHR and fat percentage, with no statistical significance in any of these parameters (Table 2). On the other hand, body mass and hip perimetry showed a slight increase after the end of training, and there was no significance. Patients who had a $12 \mathrm{~cm}$ waist perimetry

Table 1 - Caracterization of the sample of type 2 diabetics, belonging to the physical exercise program, attended at Hiperdia of Viçosa - MG

\begin{tabular}{lccc}
\hline & Male $(\mathrm{n}=\mathbf{5})$ & Female $(\mathrm{n}=\mathbf{9})$ & Total $(\mathrm{n}=\mathbf{1 4})$ \\
\hline Body mass (Kg) & $92 \pm 32$ & $79 \pm 14$ & $84 \pm 22.3$ \\
BMI & $31 \pm 10$ & $33 \pm 6$ & $33 \pm 7.9$ \\
Waist Perimetry (cm) & $107 \pm 23$ & $100 \pm 14$ & $103 \pm 17.3$ \\
Abdominal Perimetry (cm) & $113 \pm 28$ & $107 \pm 14$ & $109 \pm 19.2$ \\
Hip Perimetry & $105 \pm 13$ & $109 \pm 12$ & $108 \pm 12.5$ \\
Waist-Hip Ratio & $0.99 \pm 0.1$ & $0,92 \pm 0.06$ & $0,95 \pm 0.08$ \\
Fat percentage (\%) & $25 \pm 5$ & $37 \pm 8$ & $33 \pm 9.4$ \\
\hline
\end{tabular}

$\mathrm{N}=$ number of sample; $\mathrm{Kg}=$ kilograms; $\mathrm{BMI}=$ body mass index; $\mathrm{cm}=$ centimeters; $\%=$ percentage. Data presented as mean \pm standard deviation.

Table 2 - Anthropometric parameters of type 2 diabetic patients before and at the end of 10 weeks of supervised training

\begin{tabular}{lccc}
\hline & $\begin{array}{c}\text { Pre-training } \\
(\mathbf{n}=14)\end{array}$ & $\begin{array}{c}\text { Post-training } \\
(\mathbf{n}=14)\end{array}$ & $\boldsymbol{P}$ \\
\hline Body Mass (Kg) & $83 \pm 21.9$ & $83.9 \pm 22.4$ & 0.060 \\
BMI & $32.9 \pm 7.9$ & $32.6 \pm 7.7$ & 0.660 \\
Waist Perimetry (cm) & $103.3 \pm 17.3$ & $102.5 \pm 16.7$ & 0.908 \\
Abdominal Perimetry (cm) & $109.5 \pm 19.3$ & $108.4 \pm 17.5$ & 0.323 \\
Hip Perimetry (cm) & $108 \pm 12.5$ & $108.4 \pm 12$ & 0.521 \\
Waist-Hip Ratio & $0.95 \pm 0.08$ & $0.94 \pm 0.11$ & 0.525 \\
Fat percentage (\%) & $33.1 \pm 9.3$ & $32.1 \pm 11$ & 0.320 \\
\hline
\end{tabular}

$\mathrm{n}=$ number of the sample; $\mathrm{BMI}=$ body mass index; $\mathrm{Kg}=$ kilograms; $\mathrm{cm}=$ centimeters; $\%=$ percentage; $p=$ probability for hypothesis testing. Data presented as mean \pm standard deviation. decrease after 10 weeks of training were observed; In contrast, a patient increased their waist circumference in $4.5 \mathrm{~cm}$ after the same period. This was also observed in other measures, such as abdominal perimetry, in which a patient had a decrease of $9 \mathrm{~cm}$ and other had an increase of $6 \mathrm{~cm}$. The same happened in the hip perimetry, in which a decrease of $5 \mathrm{~cm}$ was observed in one patient and an increase of $5.3 \mathrm{~cm}$ in other one. With regard to WHR, it was found a decrease of 0.11 and an increase of 0.7 in two patients of the sample, while the largest decrease in fat percentage was $8.3 \%$ and the highest increase was $5 \%$.

When analyzed by exercise modality, it was observed that both AT and RT had low body mass loss, whereas only AT achieved lower rates of abdominal perimetry, waist circumference and WHR after 10 weeks of training, with no significant difference but clinical relevance (Table 3). On the other hand, the RT showed a slight decrease in fat percentage, but the anthropometric values, such as waist perimetry, hip perimetry and WHR, showed low increases, with no significant difference after 10 weeks of intervention with training. The largest decreases in waist perimetry, abdominal perimetry, WHR and fat percentage were found in patients belonging to the AT group, while the largest reduction in hip perimetry was observed in a patient of the RT group.

Regarding the neuromotor tests, a significant improvement in the gain of body agility was observed in total sample $(p=0.02)$, AT $(p=0.02)$ and RT ( $p=0.04)$ (Figure 1). The two best results after 10 weeks of training were volunteers belonging to the AT. The patient with the best results in the agility test obtained a decrease of 2.66 seconds after the training period compared with the initial test. No patient worsened in their indices in the body agility test.

When comparing the levels of flexibility before and after the 10 weeks of training, significant improvement was observed only in the total group ( $p=0.02)$, unlike the results found in AT ( $p=0.12)$ and RT ( $p=0.09)$. Although no significant difference was observed, these results can be considered as a relevant clinical improvement (Figure 2). The best results were observed in two patients of the RT group, in which there was

Table 3 - Anthropometric parameters of the aerobic and resistance groups before and at the end of the 10 weeks of training.

\begin{tabular}{|c|c|c|c|c|c|c|}
\hline & \multicolumn{2}{|c|}{ Aerobic Group $(n=8)$} & \multirow{2}{*}{$P$} & \multicolumn{2}{|c|}{ Resistance Group ( $n=6$ ) } & \multirow{2}{*}{$P$} \\
\hline & Pre- training & Post-training & & Pre-training & Post-training & \\
\hline Body Mass(kg) & $91.2 \pm 26.9$ & $90.3 \pm 26.5$ & 0.156 & $74.1 \pm 8.7$ & $73.5 \pm 8.2$ & 0.423 \\
\hline BMI & $36.5 \pm 8.5$ & $36.1 \pm 8.1$ & 0.125 & $28.1 \pm 3.8$ & $27.9 \pm 3.8$ & 0.432 \\
\hline Waist Perimetry $(\mathrm{cm})$ & $110 \pm 20.5$ & $106.8 \pm 20.5$ & 0.103 & $94.5 \pm 4.8$ & $96.5 \pm 8.2$ & 0.521 \\
\hline Abdominal Perimetry $(\mathrm{cm})$ & $117.25 \pm 22.6$ & $115.3 \pm 20.2$ & 0.172 & $99 \pm 4.8$ & $99 \pm 6.5$ & 0.999 \\
\hline Hip Perimetry(cm) & $114.25 \pm 12.6$ & $115.3 \pm 10.4$ & 0.541 & $98.6 \pm 4.1$ & $99 \pm 6.4$ & 0.895 \\
\hline Waist-Hip Ratio & $0.95 \pm 0.101$ & $0.92 \pm 0.13$ & 0.117 & $0.95 \pm 0.04$ & $0.97 \pm 0.06$ & 0.076 \\
\hline Fat Percentage (\%) & $38.5 \pm 8.7$ & $37.8 \pm 10.9$ & 0.668 & $27 \pm 6.0$ & $25.3 \pm 6.8$ & 0.227 \\
\hline
\end{tabular}

$\mathrm{n}=$ number of the sample; $\mathrm{kg}=$ kilograms; $\mathrm{cm}=$ centimeters; \%= percentage; $\mathrm{p}=$ probability for hypothesis testing, paired $\mathrm{t}$ test. Data presented as mean \pm standard deviation. 


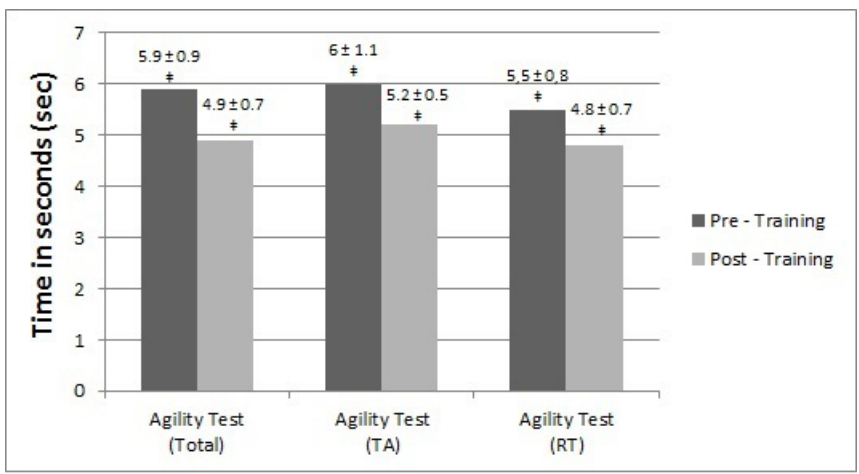

Figure 1 - Evolution of body agility levels in the total patients and separated by aerobic and resistance training before and at the end of the 10 weeks of supervised training. $\mathrm{sec}=$ seconds; $\mathrm{AT}=$ aerobic training; $\mathrm{RT}=$ resistance training; $\neq$ (Significance $p<0.05$ ), paired $t$ test. Data presented as mean \pm standard deviation.



Figure 2 - Evolution of flexibility in centimeters through Wells' bench of the total patients and separated by aerobic and resistance training, before and at the end of the 10 weeks of supervised training. $\mathrm{cm}=$ centimeters; $A T=$ aerobic training; RT = resistance training; $\neq$ (Significance $p<0,05)$, paired t test. Data presents as mean \pm standard deviation.

an evolution in the Wells' Bench of 16.5 and 15 centimeters, respectively, after the training period compared to the initial test.

\section{DISCUSSION}

The main findings in this study were the improvements found in the tests of hip flexibility through the Wells' bench, as well as gains in speed, agility and body balance after 10 weeks of aerobic and resistance exercise. It was also observed that the training period did not provide a statistically significant improvement in any of the anthropometric parameters analyzed. It is possible that a longer intervention time is fundamental to reach better anthropometric results than those obtained in this study. It was observed in the results of Krinski et al. ${ }^{(25)}$ that 53 volunteers of both genders, mean age of 64 years, participated of aerobic and resistance exercises for six months, achieving significant results of reduction of fat percentage. Other exercise prescription variables, such as the length of the training session, which could be increased from the prescribed 60 minutes, or a higher number of times weekly (five times), may be alternatives to seek better results.

Although there were no significant reductions in anthropometric parameters by some patients, physical exercise has been consolidating as an extremely important tool in the fight against obesity, associated to a dietary reeducation. ${ }^{(26)}$ The results presented can be justified by the absence of dietary control based on a calorie restriction, the weekly frequency and the moderate intensity of the exercise programs, which may not have resulted in negative energy balance necessary for loss of body mass and, consequently, reductions in anthropometric variables (Table 2). According to Myers et al. (27), the increase in caloric intake in a compensatory way is one of the factors that can influence the maintenance or even the gain of body mass in long-term exercise programs, contributing to the inefficacy in weight loss results. And according to Sigal et al. ${ }^{(28)}$, the majority of studies that have been successful in loss and control of body mass involved the combination of dietary exercises and behavioral changes, in which only the intervention with exercises tends to produce modest body mass changes.

It is also possible that the moderate intensity proposed has influenced the results. This is because high intensity exercise may influence $\mathrm{BMI}$ reduction, increasing the post-exercise metabolic rate more than its duration. High-intensity exercise has been related in the last decades to healthy weight loss because of the EPOC (excessive post-exercise oxygen consumption) effect, which provides extra energetic demand predicted in physical activity, in addition to a high metabolism magnitude during recovery, being important in weight reduction programs, although it was observed that the patients participating in the study were not prone to high intensity exercises. ${ }^{(29)}$ The justification for not using high-intensity exercises was based on the very worrying clinical pictures related to the advancement of $2 \mathrm{DM}$ complications, making it impossible for example to use the maximal ET. In addition, the study participants had low physical fitness, motor coordination and low ergometer adaptation. It is not appropriate to use the maximum repetition test to obtain the training loads. ${ }^{(30)}$

Regarding the gains in coxofemoral flexibility, the present study demonstrated a significant improvement in the total sample and when separated into groups of aerobic and resisted exercises, important improvements with clinical relevance were witnessed. This result is extremely important, given that adults tend to lose about 8 to 10 centimeters of flexibility in the hips and lumbar region. ${ }^{(31)}$ During senescence, flexibility of the hamstring muscles play a key role in postural balance, maintenance of range of motion of the hip and knees, and prevention and optimization of musculoskeletal function. ${ }^{\text {(32) }}$ Corroborating the findings of this study, it was observed with a sample of 22 women aged between 60 and 75 years, that both the strength training group and those who practiced flexibility exercises, obtained improvements in the body 
balance evaluated by the scale of Berg during 11 weeks. ${ }^{(33)}$ So it is observed that the maintenance or improvement of flexibility and muscular strength are essential in body balance.

Considering the mobility test, that assess speed, agility and body balance, the total sample and when separated in AT and RT groups, obtained significant improvement in the time of the test (Figure 2). An example of acute improvement was obtained by a subject of AT, who gained 2.66 seconds of mobility. These improvements may be due to the increase in flexibility and strength acquired by the lower limbs after the training period. ${ }^{(31)}$ Thus, both aerobic and resistance exercise were able to improve the physical capacity of these patients, leading them to a greater body dynamism and, consequently, to the improvement of the quality of life. The findings of this study corroborate those of Alves et al. ${ }^{(20)}$, that evaluated 37 women belonging to a group that performed water aerobics for three months and 37 women who were part of the control group, mean age of 78 years, in which the intervention group obtained significant improvements in the test "sitting, walking 2.44 and sitting", compared with the control group. The reported facts show that the physical exercise practiced on a regular basis allows gains in the corporal functionality and in the quality of life of its practitioners.

This study presents limitations regarding non-dietary control during the physical exercise period that may have limited the findings. Due to the fact that the volunteers had low physical conditioning and low motor coordination, a period of adaptation to the exercise routine was necessary. Besides, because they were people of low purchasing power, it was not possible to extend the intervention period, due to the financial difficulties of the volunteers to go to the Hiperdia Center. Non-inclusion of a control group may also be considered as a limitation of this study.

\section{CONCLUSIONS}

With this, we can conclude that a period of 10 weeks of supervised physical exercise was not enough to promote improvement in the anthropometric variables of patients with 2DM. However, satisfactory results were observed in the gains of speed, agility and body balance in the total sample and when separated in AT and RT, leading to the belief that both modalities result in gain of body mobility. In addition, significant advances in coxofemoral flexibility were observed in the total sample and when separated into the AT and RT groups. Our results emphasize the importance of physical exercise in maintenance, in gain of body mobility and also in hip flexibility, especially in patients with 2DM.

\section{AUTHOR'S CONTRIBUTION}

RBT: Initial idea of research, data collection, data analysis and final writing of the work;

LML: Co-orientation of the research and final revision of the text; YLX: Helped in collecting data and writing the text, in addition to performing article submission; CGL: Helped in collecting the data and in the final revision of the text; GFL:
Helped in analyzing the data and in the final revision of the text; HHTR: Helped in data collection, in the corrections required by the reviewers and in the final revision of the text

JCBM: He guided the entire development of the text and guided the overall revision of the text.

\section{CONFLICTS OF INTEREST}

The authors declare that they have no conflicts of interest.

\section{AUTHOR DETAILS}

${ }^{1}$ Master degree in the post-graduation program of Physical Education, Federal University of Viçosa (UFV), Viçosa Campus (MG), Brazil. ²PhD Adjunct Professor of the Department of Medicine and Nursing, Federal University of Viçosa (UFV), Viçosa Campus (MG), Brazil. ${ }^{3} \mathrm{PhD}$ in Physical Education, Federal University of Viçosa (UFV), Viçosa Campus (MG), Brazil.

\section{REFERENCES}

1- Silva MBG, Skare TL. Manifestações musculoesqueléticas em diabetes mellitus. Revista Brasileira de Reumatologia. 2012. 52(4): 601-609.http:// dx.doi.org/10.1590/S0482-50042012000400010.

2- Gomide NAC, Moreira OC, de Oliveira RAR, dos Santos APR, Marins JCB. Prevalência de glicemia sugestiva de diabetes mellitus e intolerância à glicemia de jejum em uma cidade do interior do Brasil. Arquivos de Ciências da Saúde da UNIPAR. 2013. 17(3): 147-152.

3- Naito R, Kasai T. Coronary artery disease in type 2 diabetes mellitus: Recent treatment strategies and future perspectives. World Journal of Cardiology. 2015. 7(3): 119-124. http://doi.org/10.4330/wjc.v7.i3.119.

4- Vila CP, Silva MEM, Simas JPN, Guimarães ACA, Parcias SR. Aptidão física funcional e nível de atenção em idosas praticantes de exercício físico. Revista Brasileira de Geriatria e Gerontologia. 2013. 16(2): 355-364. http://dx.doi.org/10.1590/S1809-98232013000200015.

5- Association AD. Standards of medical care in diabetes. Diabetes Care. 2015. 37 (Supplement1): S14-S80.

6- Gomes MDB, Neto DG, Eurico M, Tambascia MA, Fonseca RM, Rea $\mathrm{RR}$, et al. Prevalência de sobrepeso e obesidade em pacientes com diabetes mellitus do tipo 2 no Brasil: estudo multicêntrico nacional. Arquivos Brasileiros de Endocrinologia \& Metabologia. 2006. 50(1): 136144.http://dx.doi.org/10.1590/S0004-27302006000100019.

7- Fett WCR, Fett CA, Marchini JS, Moriguti JC, Ferrioli E. Composição corporal de idosas diabéticas tipo 2: antropometria vs absorcimetria de raios- $X$ de dupla energia. Revista de Nutrição. 2010. 23(5): 695-702.http://dx.doi. org/10.1590/S1415-52732010000500001.

8- Cristóvão MF, Sato APS, Fujimori E. Excesso de peso e obesidade abdominal em mulheres atendidas em Unidade da Estratégia Saúde da Família. A Revista da Escola de Enfermagem da USP. 2011. 45(spe2): 1667-1672. http://dx.doi.org/10.1590/S0080-62342011000800005.

9- lampolsky MN, Souza FIS, Sarni ROS. Influência do índice de massa corporal e da circunferência abdominal na pressão arterial sistêmica de crianças. Revista Paulista de Pediatria. 2010. 28(2): 181-187. http://dx.doi. org/10.1590/S0103-05822010000200009.

10- Frainer DES, Vasconcelos FDA, Costa LCF, Grosseman S. Body fat distribution in schoolchildren: a study using the LMS method. Revista Brasileira de Medicina do Esporte. 2013. 19(5): 317-322. http://dx.doi. org/10.1590/S1517-86922013000500003.

11- Sá MA, Gomes TM, Bentes CM, Costa SG, Rodrigues NG, Novaes JS. Efeito agudo do alongamento estático e facilitação neuromuscular proprioceptiva sobre o desempenho do número de repetições máximas em uma sessão de treino de força. Revista Motricidade. 2013. 9(4): 73-81. http://dx.doi.org/10.6063/motricidade.9(4).1198.

12- World Medical Association. Proposed Revision of the Declaration of Helsinki. Tel Aviv: World Medical Association. (mimeo.). 2000.

13- Ghorayeb N, Costa RV, Castro I, Daher DJ, Filho OJA, Oliveira MA, et al. Guidelines on exercise and sports cardiology from the Brazilian Society of Cardiology and the Brazilian Society of Sports Medicine. Arquivos Brasileiros de Cardiologia. 2013. 100 (1 Suppl 2): 1-41. http://dx.doi. org/10.1590/S1517-86922003000200002. 
14- WHO J, Consultation FE. (2003). Diet, nutrition and the prevention of chronic diseases. WHO Technical Report Series, (916): 1-60.

15- Freedman DS, Serdula MK, Srinivasan SR, Berenson GS. Relation of circumferences and skinfold thicknesses to lipid and insulin concentrations in children and adolescents: the Bogalusa Heart Study. American Journal of Clinical Nutrition. (1999). 69(2): 308-317.

16- Chagas P, Caramori P, Barcellos C, Galdino TP, Gomes I, Schwanke CHA. Associação de diferentes medidas e índices antropométricos com a carga aterosclerótica coronariana. ArquivosBrasileiro de Cardiologia. 2011. 97(5): 397-401. http://dx.doi.org/10.1590/S0066-782X2011005000093.

17- Jackson AS, Pollock ML. Practical assessment of body-composition. Physician and sportsmedicine. 1985. 13: 76.

18- Jackson AS, Pollock ML, Ward A. Generalized equations for predicting body density of women. Medicine \& Science in Sports \& Exercise. 1980. 12: $175-182$

19- Siri WE. Body composition from fluid spaces and density: analysis of methods. Techniques for measuring body composition. 1961. 61: 223-244.

20- Alves RV, Mota J, Costa MDC, Alves JGB. Aptidão física relacionada à saúde de idosos: influência da hidroginástica. Revista Brasileira de Medicina do Esporte. 2004. 10(1): 31-37. http://dx.doi.org/10.1590/ S1517-86922004000100003.

21- Moesch J, Mallmann JS, Tomé F, Vieira L, Ciqueleiro RT, Bertolini GRF. Effects of three protocols of hamstring muscle stretching and paravertebral lumbar. Revista Fisioterapia em Movimento. 2014 27(1): 85-92.http://dx.doi.org/10.1590/0103-5150.027.001.A009.

22- Colberg SR, Sigal RJ, Fernhall B, Regensteiner JG, Blissmer BJ, Rubin RR. et al. Exercise and type 2 diabetes the American College of Sports Medicine and the American Diabetes Association: joint position statement. Diabetes care. 2010. 33(12): e147-e67.http://dx.doi. org/10.2337/dc10-9990.

23- Tanaka H, Monahan KD, Seals DR. Age-predicted maximal heart rate revisited. Journal of the American College of Cardiology. 2001. 37(1): 153-156.http://dx.doi.org/10.1016/S0735-1097(00)01054-8.

24- Borg GA. Psychophysical bases of perceived exertion. Medicine \& Science in Sports \& Exercise. 1982. 14(5): 377- 381.
25- Krinski K, Elsangedy HM, Nardo JN, Soares IA. Efeito do exercício aeróbio e resistido no perfil antropométrico e respostas cardiovasculares de idosos portadores de hipertensão. Acta Scientiarum. Health Sciences. 2006. 28(1). http://dx.doi.org/10.4025/actascihealthsci.v28i1.1093

26- Tresierras MA, Balady GJ. Resistance training in the treatment of diabetes and obesity: mechanisms and outcomes. Journal of cardiopulmonary rehabilitation and prevention's. 2009. 29(2): 67-75.http://dx.doi.org /10.1097/HCR.0b013e318199ff69.

27- Myers CA, Johnson WD, Earnest CP, Rood JC, Tudor-Locke C, Johannsen $\mathrm{NM}$, et al.. Examination of mechanisms (E-MECHANIC) of exercise-induced weight compensation: study protocol for a randomized controlled trial. Trials. 2014. 15: 212.http://dx.doi.org /10.1186/1745-6215-15-212.

28- Sigal RJ, Kenny GP, Wasserman DH, Castaneda-Sceppa C, White RD. Physical activity/exercise and Type 2 diabetes A consensus statement from the American Diabetes Association. Diabetes care. 2006. 29(6): 1433-1438.http://dx.doi.org /10.2337/dc06-9910.

29- Foureaux G, Pinto KMC, Dâmaso A. Efeito do consumo excessivo de oxigênio após exercício e da taxa metabólica de repouso no gasto energético. Revista Brasileira de Medicina do Esporte. 2006. 12(6): 393398.http://dx.doi.org/10.1590/S1517-86922006000600018.

30- De Sousa RAL, Santos NVS, Pardono E. Redução da glicemia através de exercício resistido de alta intensidade em indivíduos com Diabetes Mellitus tipo 2. Revista Brasileira de Prescrição e Fisiologia do Exercício. 2014. 8(50): 3 .

31- Shephard RJ. Aging and Exercise. In: Encyclopedia of Sports Medicine and Science, T.D.Fahey (Editor). Internet Society for Sport Science: http:// sportsci.org. 1998. 7 March.

32- Brasileiro JS, Faria AF, Queiroz LL. Influência do resfriamento e do aquecimento local na flexibilidade dos músculos isquiotibiais. Rev Bras Fisioter. 2007 janeiro;11(1): 57-61.

33- Albino ILR, Freitas CR, Teixeira AR, Gonçalves AK, Santos AMPV, Bós ÂJG. (2012). Influência do treinamento de força muscular e de flexibilidade articular sobre o equilíbrio corporal em idosas. Revista Brasileira de Geriatria e Gerontologia.15(1): 17-25. http://dx.doi.org/10.1590/S180998232012000100003. 